\section{Effect of two bottom fertilizers and previous crop on yield of durum wheat breeding seed (Triticum durum Desf.)}

\author{
Nadia Chiahi, ${ }^{1}$ Louhichi Brinis ${ }^{2}$ \\ ${ }^{1}$ Laboratory for Terrestrial and Aquatic \\ Ecosystems, Mohamed-Cherif \\ Messaadia University, Souk Ahras; \\ ${ }^{2}$ Laboratory of Plant Breeding, Faculty \\ Natural Sciences and Life University, \\ BADJI Mokhtar, UBM, Annaba, Algeria
}

\begin{abstract}
To improve the yield of durum wheat seed (Triticum durum Desf.), seven varieties were grown in an experimental field (Tifech region in Souk Ahras). The study focused on planting the varieties on two cropping precedents (sorghum and fallow grazing), in addition to the use of two bottom fertilizers, one potassic (Fosfactyl) and the other phoshonitrogen, (DAP). The analysis of the results showed a clear improvement in grain yields in the varieties harvested from the previous crop (Sorgho) and having received Fosfactyl as fertilizer. The best grain yields were displayed by the Carioca, Boussallem and Sersou varieties. After harvest, the study of soil parameters of the respective parcels showed soil with a sandy loam texture, with a low organic matter, with a slightly alkaline $\mathrm{pH}$, while being low in salts.
\end{abstract}

\section{Introduction}

The multiplication of cereals in Algeria is dependent on several abiotic factors (mainly precipitation and soil pedological nature) and biotic (genetic potentialities of varieties), expressed by their phenotypic variation and the difference in their yields. In addition, the intervention of farmers by tillage, fertilizer input and phytosanitary treatments greatly influence the production from one year to another. ${ }^{1}$ The fact that professionals in the field, in collaboration with the Ministry of Agriculture and other agencies, are developing new methods such as the concept of viability/vigor of seeds, adaptation to biotic and abiotic stresses Technological quality and rational fertilization. $^{2}$ The difference in agro-climatic zones in Algeria also accentuates the fluctuation of this production from one region to another. This problem is based on the fact that the agro-climatic potentialities are poorly known. It is therefore almost impossible to foresee the crops to be developed in agroclimatic zones. It is equally evident that planning forecasts could be little related to the actual potentialities of these areas. ${ }^{3}$

The production of wheat in Algeria is characterized by very unstable fluctuations. It shows no particular trend, but from the 1994/1995 season onwards it undergoes a more or less linear trend. This sudden trend could be due to one of the two main reasons, namely a marked improvement in rainfall and the adoption of new economic reforms during the period (1989-1995), the repercussions of which can be seen from $1994 .{ }^{4}$ But if we analyze the effect of all these factors, we can limit the influence of certain factors where the multiplier can intervene widely and maximize the production of these cereals, namely. Planting of seedlings, with plowing, bottom fertilizers, selection of varieties and their doses of seedlings, cover fertilizers, phytosanitary treatment by the use mainly of herbicides and according to the regions of insecticide and even of fungicide. Apart from these factors, linked to field cultivation, we can also add the seed storage conditions at the C.C.L.S. level. Which we describe as postharvest factors and which can greatly influence seed viability and vigor. All these reasons led us to consider how far the multiplier can improve cereal seed production! By adopting a system of cultivation grouping several parameters that it can vary itself.

In order to do this, we decided to install such a system in a region characterized by the production of cereal farming associated with the Tifech region $\left(36^{\circ} 14\right.$ latitude North and $7^{\circ} 10$ longitude East $25 \mathrm{~km}$ Northeast wilaya of Souk Ahras-Algeria).

\section{Materials and Methods}

\section{Experimentation on field: descrip- tion and location of the study site}

The experimental real-life study was carried out at the Yousfi pilot farm in the Souk Ahras region, north-east of Algeria $36^{\circ} 14$ latitude North and $7^{\circ} 10$ longitude East (Figure 1). The Yousfi Tayeb pilot farm, located in a basin and surrounded by wooded mountains, is characterized by very variable temperatures according to the seasons, with a cold climate in winter and warm in summer. Average rainfall exceeds $600 \mathrm{~mm} /$ year, and mostly abundant in winter, from December to February, and frosts are very present in February and March. ${ }^{5}$

\section{Installation of the test}

The year 2012, date corresponding to the beginning of this thesis and as it was
Correspondence: Nadia Chiahi, Laboratory for Terrestrial and Aquatic Ecosystems, Mohamed-Cherif Messaadia University, Souk Ahras, Algeria.

Tel./Fax: +213.37.715166

E-mail: nchiahidz@gmail.com

Key words: durum wheat, yield, soil, fertilization, varieties, crops, previous crop.

Contributions: the authors contributed equally.

Conflict of interest: the authors declare no potential conflict of interest.

Funding: none.

Received for publication: 10 July 2018.

Revision received: 31 July 2018.

Accepted for publication: 31 July 2018.

This work is licensed under a Creative Commons Attribution-NonCommercial 4.0 International License (CC BY-NC 4.0).

(C) Copyright N. Chiahi and L. Brinis 2019

Licensee PAGEPress srl, Italy

International Journal of Plant Biology 2019; 10:7308 doi:10.4081/pb.2019.7308

planned in the planning of the tasks and the methodology of the work to be carried out.

A field trial involved seeding seven varieties of durum wheat at the pilot farm Yousfi Tayeb of Tifech Souk Ahras Algeria.

Seeds of five varieties (Boussallem, Gtadur, Ouarsenis, Sersou and Waha) were delivered to us by the CCLS of Souk Ahras. Seeds of the local MBB variety were brought back from the CCLS GUELMA, in addition to the Carioca variety seed, which has been proven to be very productive in the region, has been provided by one individual along with one of the bottom fertilizers, DAP (Diamonium of Phosphate). The seeds of the varieties were sown on two preceding different crops: Sorghum and fallow grazing. The two neighboring plots simultaneously received two different bottom fertilizers, in addition to the DAP already mentioned, Fosfactyl was used.

\section{Experimental apparatus}

For more representativeness and less variability, we opted for a BAC in split plot. The area of each large plot (Sorghum and fallow pastures) is: $700 \mathrm{~m}^{2} \times 2=1400 \mathrm{~m}^{2}$

Each variety was represented twice in mini plots with an area of $25 \mathrm{~m}^{2}$. Each mini plot was sown with a dose of $350 \mathrm{~g}$ of seeds at the rate of $(140 \mathrm{~kg} / \mathrm{ha})$ arranged on 7 lines. The mini plots were separated by a distance of $1 \mathrm{~m}$ (Figures 2 and 3 ). 


\section{Conduct of the test}

\section{Date of sowing}

Planting was carried out respectively on 11 and 12 January 2012 for grazing fallow plot and 15 and 16 January 2012 for the second Sorgho plot.

\section{Phytosanitary treatment}

Treatment of the plots by a mixed weedker DIALEN at the rate of $1 \mathrm{~L} / \mathrm{ha}$. Plots were treated with the same herbicide (Dialen super) on $02 / 05 / 2012$ to reduce interactions of other factors.

\section{Crops}

The harvest was carried out 180 days after sowing, simultaneously for both plots, allowing us to determine the grain weight of each mini plot.

\section{Statistical analysis}

Interpretation of the harvest results was performed using Statistical Analysis System (SAS) software version 9.

\section{Results and Discussion}

\section{Yield on previous crops}

The statistical treatment shows the clear difference in the crop on the two preceding crops; In fact, the crop on the previous crop (Sorgho) with an average of $6.22 \mathrm{Kg}(24.88$ $\mathrm{qx} / \mathrm{ha}$ ) was better than that recorded on the previous crop (pasture fallow) with only an average around $4.50 \mathrm{~kg}$ (18qx/ha). This difference may be due to a few factors, mainly related to the cultivation of Sorghum, among them the following ones. The cultivation period of Sorghum grown in warm weather, lack of precipitation and lack of irrigation prevents nitrogen leaching. ${ }^{6}$ So the mineralization of the soil in full drought does not favor the absorption of all the available nitrogen, which leads to the enrichment of the soil by this mineral.

The behavior of sorghum in rotation: It has a greater nitrogen supplement than in the case of maize, the straws of all crops are recycled. The photosynthetic nature of the plant such as corn, sorghum is a $\mathrm{C} 4$ plant that allows it to unfold its photosynthetic system and thus its metabolism during dry periods or the tolerance of $\mathrm{C} 3$ plants by closing of stomata and decreased absorption, induces side effects. ${ }^{6}$

\section{Yield with fertilizers}

Regarding fertilizer, although the grain yield harvest after the use of both fertilizers was almost similar, the plots receiving Fosfactyl recorded a slightly higher crop with an average around $5.50 \mathrm{~kg}(22 \mathrm{qx} / \mathrm{ha})$ than that obtained on plots that were fertilized by DAP, although the statistical treatment could not detect a significant difference in the harvest between plots that had been fertilized differently. In the field it was remarkable, the plots with Fosfactyl were better than those with the DAP. This slight difference could be due to the variation in the mineral composition of the two fertilizers. On the one hand, Fosfactyl contains potassium $\mathrm{K}$, in spite of the fact that the wheat has little need for this element. mobile $(\mathrm{K}+$ ion) dissolved in intracellular fluid (especially in the vacuole) plays roles of extreme importance in the plant, such as the maintenance of

Table 1. The difference in grain yields of varieties.

\begin{tabular}{lcccc} 
T Grouping & Average & Nb & Variety \\
& A & 7.4500 & V2 & 8 \\
& A & & & \\
B & A & 6.7250 & V1 & 8 \\
B & & & & \\
\hline B & C & 5.7000 & V6 & 8 \\
& C & & & \\
D & C & 4.7625 & V5 & 8 \\
D & & & & \\
\hline D & & 4.5375 & V7 & 8 \\
D & & & & \\
D & & 4.1375 & V3 & 8 \\
D & & & & \\
\hline D & & 4.1125 & V4 & 8 \\
\hline
\end{tabular}

Averages with the same letter are not very different. Alpha: 0.05 ; Error Degrees of liberty: 26; Middle Square Error: 1.008736; Critical value of t: 2.05553; Smallest significant difference: 1.0322. osmotic pressure in the turgid vacuoles, and decreases in some cases, reducing sweating the risk of wilting. ${ }^{7}$ This clearly proves its relation with the hormonal action of $\mathrm{ABA}$ (abscisic acid) in tolerance to certain abiotic stresses, such as water deficiency or cold. ${ }^{8}$ On the other hand, Fosfactyl contains sulfur

Table 2. The difference in yields of the previous crop: fallow.

\begin{tabular}{|c|c|c|c|c|}
\hline \multicolumn{2}{|c|}{ T Grouping } & Average & $\mathrm{Nb}$ & Variety \\
\hline \multicolumn{2}{|r|}{$\begin{array}{l}\mathrm{A} \\
\mathrm{A}\end{array}$} & 6.1750 & 4 & V2 \\
\hline \multicolumn{2}{|r|}{$\begin{array}{l}\mathrm{A} \\
\mathrm{A}\end{array}$} & 6.0500 & 4 & V1 \\
\hline $\begin{array}{l}\text { B } \\
\text { B }\end{array}$ & $\begin{array}{l}\mathrm{A} \\
\mathrm{A}\end{array}$ & 4.8750 & 4 & V6 \\
\hline $\begin{array}{l}\text { B } \\
\text { B }\end{array}$ & $\begin{array}{ll}\text { A } & \text { C } \\
& \text { C }\end{array}$ & 4.3500 & 4 & V5 \\
\hline $\begin{array}{l}\text { B } \\
\text { B }\end{array}$ & $\begin{array}{l}\text { C } \\
\text { C }\end{array}$ & 3.6750 & 4 & $\mathrm{~V} 7$ \\
\hline B & $\begin{array}{l}\mathrm{C} \\
\mathrm{C}\end{array}$ & 3.4000 & 4 & V3 \\
\hline & $\mathrm{C}$ & 2.7500 & 4 & V4 \\
\hline
\end{tabular}

Averages with the same letter are not very different.Alpha: 0.05 ; Error Degrees of liberty: 12; Middle Square Error: 1.521429; Critical value of t: 2.17881; Smallest significant difference: 1.9003.

Table 3. The difference in the yield of varieties in the previous crop: Sorghum.

\begin{tabular}{lccc} 
T Grouping & Average & $\mathrm{Nb}$ & Engrais \\
A & 6.2929 & 14 & Fosfactyl \\
A & & & \\
A & 6.1571 & 14 & DAP \\
\hline
\end{tabular}

Averages with the same letter are not very different. Alpha: 0.05 ; Error Degrees of liberty: 2; Middle Square Error: 0.540357; Critical value of t: 4.30265; Smallest significant difference: 1.1954 .

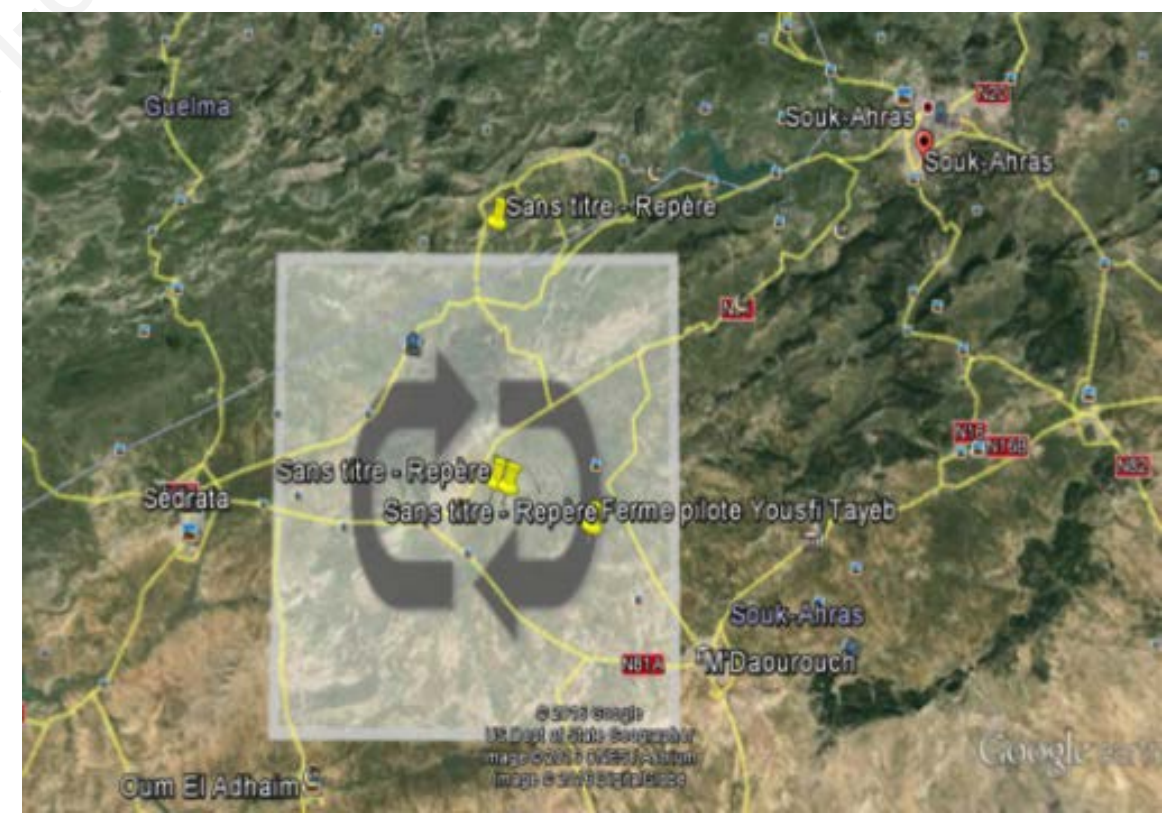

Figure 1. Satellite image of the experimental site: Yousfi Tayeb pilot farm, Algeria. 
(S) and wheat crops require such an element for good growth. ${ }^{9}$

\section{Variety yield}

For the behavior of the varieties we obtained three groups of varieties according to their harvest (weight of their grains).

Group Carioca (V2) and Boussallem (V1), which showed the best weights, especially the Carioca variety with $7.45 \mathrm{~kg}$ (30 $\mathrm{qx} / \mathrm{ha}$ ), could qualify it by variety of very good yields in grains.

Second group: These varieties were followed by Sersou and Ouarsenis with good yields of around $6.72 \mathrm{~kg}(27 \mathrm{qx} / \mathrm{ha})$ and 5.70 $\mathrm{kg}$ (23 qx/ha). Finally, the other varieties can be classified in the last group (3rd) which showed average yields, Waha, Gtadur and MBB which did not even reach $4.20 \mathrm{~kg}$ (17 qx/ha).

\section{Difference in yields in the previous crop fallow}

Regarding the behavior of the varieties on each previous crop and the influence of fertilizers on the crops, the same result is always reported, which is the low yield of grain recorded on the previous crop fallow and with the same classification of the varieties (in three groups) (Table 1). The best yields at Carioca and Boussallem were around $6.1 \mathrm{~kg}$ (24.40 qx/ha) followed by the Sersou and Ouarsenis varieties with weights around $4.50 \mathrm{~kg}$ (18 qx/ha) and finally the Waha, Gtadur and MBB varieties displayed the weights of the lowest grains not even reaching $3 \mathrm{~kg}(12 \mathrm{qx} / \mathrm{ha})$.

\section{Difference in yields between fertiliz- ers on fallow}

For fertilizers, the yield with application of Fosfactyl slightly exceeds that of the plot (sorghum) which received the DAP, with $4.60 \mathrm{~kg}$ (18.40) qx/ha (Table 2).

\section{The yield in the pre-crop Sorghum}

While the best grain weights were recorded on the previous crop (Sorgho) and still in the Carioca V2 variety, which stands out in a separate group with $8.72 \mathrm{~kg}$ (35 $\mathrm{qx} / \mathrm{ha}$ ) followed by the 2 nd group with the same varieties Boussallem V1 with $7.40 \mathrm{~kg}$ (30 qx/ha) and Sersou V6, the third group with average harvests of the same MBB, Waha and Gtadur varieties (Table 3).

\section{Yields with sorghum fertilizer}

Again, the difference between yields does not appear with the application of the two fertilizers but always with the classification of Fosfactyl first with $6.30 \mathrm{~kg}(25.20$ qx/ha) followed by DAP with $6.16 \mathrm{~kg}$ (24.64 qx/ha).

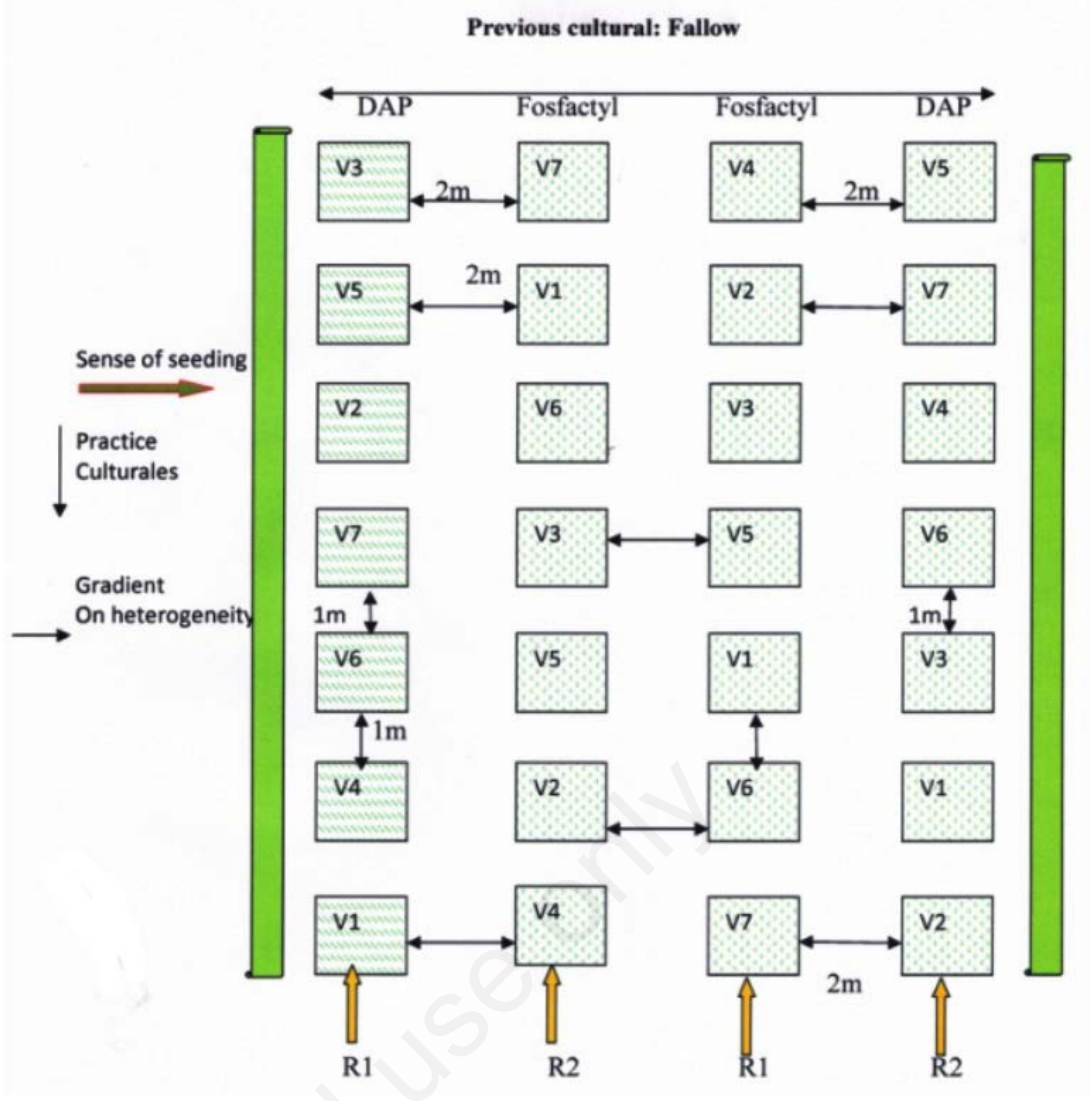

Figure 2. Device of the experimental trial of the previous crop fallow. V1, Boussallem; V2, Carioca; V3, Gtadur; V4, MBB; V5, Ouarsenis; V6, Sersou; V7, Waha.

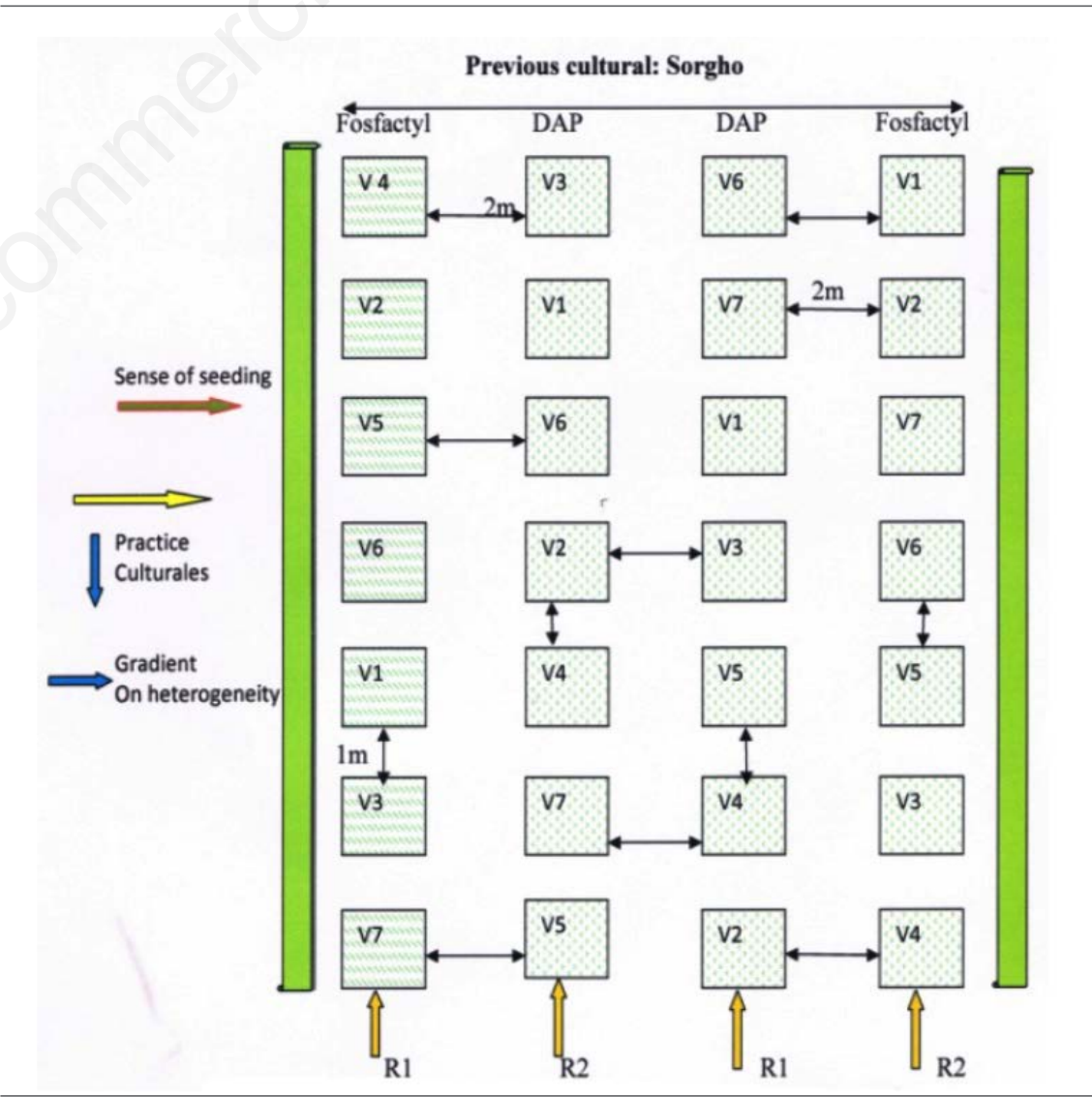

Figure 3. Device of the experimental test of the pre-cultural Sorgho. V1, Boussallem; V2, Carioca; V3, Gtadur; V4, MBB; V5, Ouarsenis; V6, Sersou; V7, Waha. 


\section{Conclusions}

In order to improve durum wheat in the cereal area at the Yousfi Tayeb Tifech pilot farm (Souk Ahras, Algeria), planting of seven varieties on two previous crops (Grazing Fallow and Sorghum) Of the use of two fertilizers, one potash: Fosfactyl, the other binary (phospho-nitrogen): the DAP led to different crops between varieties and plots. By comparing the average of the grain yields of the varieties, we have deduced the following results.

The difference in grain yields on the two preceding crops or the best grain yields were displayed on the previous Sorghum crop. No differences in yields were found between the yields of the varieties with the incorporation of the two fertilizers, although the classification of the varieties was better following the fertilization by Fosfactyl, noted both in the set (of the two Previous crops) than within each plot.

A clear difference between the grain yields of the varieties, with a sometimes similar behavior towards the influence of the two factors of variation, previous crop and bottom fertilizer, a behavior that can be explained by the following.

The superiority of certain varieties introduced mainly Carioca, followed by
Sersou (Simeto.) And Ouarsenis (Ofanto).

In addition to its superiority, the local variety Boussallem showed a very good regularity in its yield, both on the two plots (previous crops) and in each plot with the implication of the influence of the fertilizer.

The introduced varieties Waha, Gtadur and especially the MBB variety showed the lowest grain yields.

\section{References}

1. Chiahi N, Brinis L, Tahar A. Varietal study of vigor and viability on three varieties of durum wheat (Triticum durum Desf.) Stored for different periods in a semi-arid zone. International Seminar on "Protection and preservation of Saharan ecosystems" on 13, 14 and 15 December 2009 at the KASDI Merbah-Ouargla University, Algeria.

2. Brinis L. 3rd Meetings of the Podiums of FERTIAL: Fertilization of cereals \& food safety: FERTIAL News: Magazine published by FERTIAL. $\mathrm{N}^{\circ} 25$ February 2012.

3. Derouiche G. B N E D E R (National Bureau of Studies for Rural Development): Climate risks and Algerian agriculture. Seminar AlgiersHotel El-Aurassi 10 June 2007.
4. Kellou R. Analysis of the Algerian durum wheat market and export opportunities for French cereal producers in the framework of the QualiMediterranean competitiveness cluster. The case of cooperatives in the south of France, Occitan cooperative group and Audecoop - Montpellier: CIHEAMIAMM, 2008. 168p.

5. ONM Synthesis report of the National Meteorological Office year 2013.

6. Brisson N, Gervois ZR, Benoit M. Climate change and agricultural practices Perspectives on the past and the future, In Seminary STICS, 20-22 March 2007, Reims, France.

7. Soltner D. Large-scale crop production. Agricultural science and technology collection, Paris. 20th ed. 2005. 472 p.

8. Gravot A. Plant Physiology Pedagogical Team University of Rennes 1; UMR 118-APBV INRAAgrocampus West-University of Rennes 1. 2009.

9. Mallarino AP, Bordoli JM, Borges R. Phosphorus and potassium placement effects on early growth and nutrient uptake of no -till vorn and relationships with grain yield. Agro J 1999;91:3-45. 